\title{
Menolak Wabah dalam Serat Ronggo Sutrasno Karya Sunan Kalijaga
}

\author{
Muhammad Abdullah \\ Fakultas Ilmu Budaya, Universitas Diponegoro \\ abdullahabah47@gmail.com
}

\begin{abstract}
One of the Javanese texts with esoteric value is the Ronggasutrasna Kidungan Fiber which is kept by the Surakarta Sastra Lestari Foundation. Serat Kidungan Ronggasutasna is a Javanese script in which there is a text in the form of fibers written by Sunan Kalijaga written together with Ronggasutrasna and then published by Tan Gun Swi. This manuscript is a compilation of a number of songs including Rumeksa Ing Wengi (KRIW), Padanghyangan Kidungan (and those of the dhedhemit ratuning), and other hymns. However, the KRIW text is not an original manuscript written by Sunan Kalijaga. This is evidenced by the existence of other KRIW texts in PNRI presented in handwriting. Serat Kidung Ranggasutrasna is the song of the 'kid' of old fibers which is a representation of esoteric values and Islamic symbolism of the spiritual messages of Kanjeng Sunan Kalijaga. After the authors examined the contents of the text, the authors concluded that most of the Ranggasutrasna's fiber of the Kidungan text contains the magic power plan in the form of spells of rebel, repellent witchcraft, sorcery, babysitting, escaping from the bondage of debt, self defense, war ethos, worship ethos, and treatment system in Javanese culture. Fiber Kidung Ranggasutrasna belongs to the piwulang script which is presented in the form of Javanese song.
\end{abstract}

Keywords: Song of Ranggasutasna; esoteric; magical power; local wisdom.

\section{Intisari}

Salah satu naskah Jawa yang bernilai esoteris adalah Serat Kidungan Ronggasutrasna yang disimpan oleh Yayasan Sastra Lestari Surakarta. Serat Kidungan Ronggasutasna adalah sebuah naskah Jawa yang di dalamnya terdapat sebuah teks berbentuk serat hasil tulisan Sunan Kalijaga yang disusun bersama Ronggasutrasna dan kemudian diterbitkan oleh Tan Gun Swi. Naskah ini merupakan kompilasi dari beberapa kidungan yang di antaranya Kidungan Rumeksa Ing Wengi (KRIW), Kidungan Padanghyangan (danyanghyangan para ratuning dhedhemit), dan kidung-kidung lainnya. Namun teks KRIW bukan merupakan naskah asli tulisan Sunan Kalijaga. Hal ini dibuktikan dengan adanya teks $K R I W$ lain dalam PNRI yang disajikan dalam tulisan tangan. Serat Kidung Ranggasutrasna merupakan nyanyian 'kidungan' serat kuna yang merupakan representasi nilai-nilai esoteris dan simbolisme Islam dari pesan-pesan spiritual Kanjeng Sunan Kalijaga. Setelah penulis meneliti isi teks, penulis menyimpulkan bahwa sebagian besar teks Serat Kidungan Ranggasutrasna berisi tentang piwulang kekuatan gaib yang berupa mantra-mantra tolak balak, penolak santet, tenung, penjaga bayi, kluar dari belenggu hutang, bela diri, etos perang, etos ibadah, dan sistem pengobatan dalam budaya Jawa. Serat Kidung Ranggasutrasna tergolong ke dalam naskah piwulang yang disajikan dalam bentuk tembang Jawa.

Kata kunci: Kidung Ranggasutasna; esoteris; kekuatan gaib; kearifan lokal. 


\section{Pendahuluan}

Warisan budaya nenek moyang yang harus dilestarikan eksisitensinya pada masa kini adalah naskah-naskah klasik. Keunggulan naskah klasik ini justru terletak pada konsistensi teksnya yang mampu menggoreskan pikiran-pikiran masyarakat masa lalu yang berupa falsafah hidup dan kearifan lokal. Aspek moral inilah yang cukup berharga dan bermakna, karena tidak dimiliki oleh masyarakat mana pun. Di antara naskah yang bernilai kearifan lokal adalah Serat Kidungan Ronggasutrasna yang disimpan oleh Yayasan Sastra Lestari Surakarta. Serat Kidungan Ronggasutasna adalah sebuah naskah Jawa yang di dalamnya terdapat sebuah teks berbentuk serat hasil tulisan Sunan Kalijaga yang disusun bersama Ronggasutrasna dan kemudian diterbitkan oleh Tan Gun Swi. Naskah ini merupakan kompilasi dari beberapa kidungan yang di antaranya Kidungan Rumeksa Ing Wengi (KRIW), Kidungan Padanghyangan (danyanghyangan para ratuning dhedhemit), dan kidung-kidung lainnya.

Dalam katalog PNRI penulis menemukan teks $K R I W$ yang disajikan dalam tulisan tangan dengan huruf Arab-pegon, namun teks $K R I W$ bukan merupakan naskah asli tulisan Sunan Kalijaga. Serat Kidung Ranggasutrasna tergolong ke dalam naskah piwulang yang disajikan dalam bentuk tembang Jawa. Penulis dapat mengatakan bahwa teks ini sebuah mantra Jawa yang terdapat dalam Serat Kidung Ranggasutrasna bergenre puisi dan memiliki kekutan gaib. Nilai-nilai kekuatan gaib ini tampak dalam beberapa aspek esoteris teks yang dapat diungkapkan untuk dunia pengobatan, penolak balak, dan pendekatan ibadah. Teks tertulis Kidung Rangasutrasna ini hampir sama isinya dengan sebuah teks Pencak Silat Harimau Putih, sebuah teks terpisah dari tradisi sastra pesantren.

Teks Pencak Silat Hari Mau Putih ajarannya berakar dari kalimat Tahlil La Ilaha Illallah, sebagai bacaan wirid dalam praktek bela dirinya. Ajaran dalam Silat Harimau Putih merupakan warisan esoteric dari ajaran Prabu Siliwangi, dari Jawa Barat. Tradisi lisan Pencak Silat Harimau Putih dapat dipakai untuk membela diri, menjaga diri, dan pembuka jalan hidup, antara sesama nanusia. Inti dari Pencak Silat Harimau Putih adalah pembacaan wirid tahlil, La ilaha ilallah yaitu kalimat toyyibah yang menafikan Tuhan-tuhan, kecuali Allah SWT. Dalam prakteknya, pencak silat 
Harimau putih membaca kalimat tahlil tersebut untuk tujuan pendekatan kepada Allah SWT. Pencak silat Harimau putih para pendekarnya membacanya sambil disertai gerak langkah kaki dan gerak tangan. Hal itu di samping berfungsi sebagai olah raga dan hiburan, tetapi juga berfungsi sebagai resitasi, sarana peribadatan. Salah satu kelebihan teks yang dilisankan dalam Silat Harimau Putih adalah adanya kekuatan gaib yang ditimbulkannya. Relevansi kuat antara teks Kidung Ranggasutrasna dengan teks Harimau Putih adalah adanya nuansa kekuatan gaib yang lahir dari tradisi pembacaan keduanya teks itu. Adanya kekuatan gaib ini merupakan aspek esoteris teks yang banyak terdapat dalam teks keagamaan, di samping aspek eksoterisnya. Namun, ternyata dalam naskah Jawa tewrdapat serat kidung yang kuat sekali nuansa esoteriknya. Naskah tersebut adalah Serat Kidung Ranggasutrasna karya Kanjeng Sunan Kalijaga.

Kidungan, Ronggasutrasna merupakan sastra lama berbahasa Jawa yang didalamnya berisi tentang mantra-mantra dan doa untuk menolak bahaya atau menyembuhkan dari bahaya. Mantra mantra dalam naskah $K R$ mengandung nilainilai mistik, seperti menghindari bahaya santet, guna-guna dan gangguan magis lainnya.

$K R$ adalah sebuah naskah cetakan yang di dalamnya terdapat sebuah teks berbentuk serat ${ }^{1}$ hasil tulisan Sunan Kalijaga yang disusun bersama Ronggasutrasna ${ }^{2}$ dan kemudian diterbitkan oleh Tan Gun Swi. $K R$ ini merupakan gabungan dari beberapa kidungan yang di antaranya Kidungan Rumeksa Ing Wengi (KRIW), Kidungan Padanghyangan (danyanghyangan para ratuning dhedhemit), dan kidungkidung lainnya yang disusun Sunan Kalijaga bersama Ronggasutrasna. Dalam katalog PNRI penulis menemukan teks $K R I W$ yang disajikan dalam tulisan tangan dengan huruf Arab-pegon, namun teks $K R I W$ bukan merupakan naskah asli tulisan Sunan Kalijaga, hal ini dibuktikan dengan adanya teks KRIW lain dalam PNRI yang disajikan dalam tulisan tangan dan berjumlah delapan teks. Dari delapan teks yang ada hanya ada satu teks yang jelas dan dapat dijadikan bahan penelitian.

Isi $K R$ dalam katalog Yayasan Sastra Lestari nomor naskah 594 termuat ringkasan isi $K R$, bahwa $K R$ merupakan nyanyian 'kidungan' serat kuna yang

\footnotetext{
${ }^{1}$ Serat adalah karya sastra (Jawa) lama dan biasanya mempunyai tema pokok berupa ajaran atau nasehat(Endraswara, 2003:12)

${ }^{2}$ Dalam naskah tertulis kidungan disusun oleh Sunan Kalijaga: wali Allah, bersama dengan susunan Kyai Ronggasutrasna: pujangga kitab induk dari Gusti Kangjeng Ratu Pambayun, putri di Keraton Surakarta Adiningrat.
} 
merupakan simbolisme Islam dan tuntunan Sunan Kalijaga mengenai cara menyembah kepada Allah SWT. Akan tetapi, setelah penulis membaca isi teks, penulis menyimpulkan bahwa sebagian besar teks $K R$ berisi tentang mantra tolak bala. $K R$ tergolong ke dalam naskah piwulang yang disajikan dalam bentuk tembang Jawa. Penulis dapat mengatakan teks ini sebuah mantra karena syair yang terdapat dalam $K R$ bergenre puisi dan memiliki kekutan gaib. Aspek esoterik mantra yang terdapat dalam teks $K R$ lah yang membuat penulis tertarik meneliti teks $K R$.

\section{Metode Penelitian}

Metode yang dipakai dalam penelitian ini adalah metode filologi dan metode analisis isi. Metode filologi dipakai untuk meneliti aspek kodikologis dan tekstologis naskah Kidung Rangga Sutrasna. Metode filologi di sini yang dipakai adalah 1) deskrispsi naskah, 2) Transliteasi Naskah, 3) Suntingan gteks, dan 4) Translasi teks. Sedang metode analisis isi dipakai untuk menganalisis aspek konten naskah. Pada pfrakteiknhya metode ini berusaha mengungkapkan aspek batiniah (isi) teks secara mendalam. Baik meliputi kandjungan dan pesan-pesan moral di dalamnya, maupun aspek batiniah (esoteris) teks.

\section{Hasil dan Pembahasan}

\section{Aspek Esoteris Serat Kidung Ranggsutrasna}

$K R$ adalah sebuah naskah yang didalamnya terdapat satu teks sastra lama berbahasa Jawa berbentuk tembang yang merupakan simbolisme Islam yang mengandung mantra-mantra. Kidung Ronggasutrasna dapat dikatakan sebagai kidung mantra karena jika kidung ini diucapkan dengan keyakinan yang tinggi akan menghasilkan kekuatan gaib. Dalam Kamus Besar Bahasa Indonesia (KBBI) arti kata mantra adalah susunan kata berunsur puisi (seperti rima, irama) yang dianggap mengandung kekuatan gaib, yang biasanya diucapkan oleh dukun atau pawang untuk menandingi kekutan gaib yang lain. Pengertian lain menyebutkan bahwa mantra adalah sesuatu yang lahir dari masyarakat sebagai perwujudan dari keyakinan atau kepercayaan masyarakat.

Penulis membedakannya dengan cara melihat sudut keruntutan kalimatnya. Misalnya bagian yang berupa mantra seperti "Nabi Ibrahim nyawa | Idris ing rambutku | Bagendha Li kulit ingwang" yang artinya "Nabi Ibrahim jiwaku|Idris di 
rambutku|Baginda Ali Kulitku" atau pada bagian "ywa marang kaki jabang | sarap wangke sarap wedang sarap awu | padha sira suminggaha" artinya "jangan kepada ananda bayi | sarap bangkai sarap minuman sarap abu | kamu semua menyingkirlah". Kedua kalimat tersebut tidak runtut susunan kalimatnya sehinga bisa dikatakan sebagai mantra. Sedangkan bagian yang bukan mantra susunan kalimatmya runtut "yèn anangis lare iku | lela-lelanên lan dhikir" artinya "Apabila ada anak menangis|buailah dan berdzikirlah"

Selain mantra dan doa dalam teks $K R$ terdapat pada yang isinya pengajaran mengenai ilmu Islam yaitu mengenai rukun Iman, tersurat dalam pupuh Dhandhanggula (2) pada 1-3 yang teksnya sebagai berikut.

"sipat iman wa mantubilahi | têgêsipun pracaya ing Allah | ing Pangeran sajatine | ya Pangeran kang Agung | kang akarya bumi lan langit | angganjar lawan niksa | mring manungsa sagung | langgêng tur murba misesa| maha suci angganjar paring rijêki | aniksa angapura ||"

"kaping kalih wa malaikati | têgêsipun pracaya malekat | asna punika têgêse | ingutus ing Hyang Agung | pakaryane anênulisi | marang kawulanira| kang dosa lit agung | kang karya purba wisesa | neka-neka gawene sawiji-wiji | sakèhing malaekat \|”

"kaping tigane wa kutubihi | têgêsipun pracaya ing kitab | kang tinurunakên kabèh | kitab Adam sapuluh | Nabi Êsis sèkêt winilis | anênggih punang kitab| Idris têlung puluh | Ibrahim sapuluh kitab | Taurat Musa Dawud Jabur Isa Injil | kitab Kuran Mukhamad ||"

Artinya:

Sifat iman wa mantubilahi| artinya percaya kepada Allah|pada Pangeran sejatinya|yaitu Pangeran Yang Agung| Pencipta bumi dan langit|yang mengganjar dan memberi|terhadap manusia agung dan bijaksana|Maha suci Pemberi Rezeki|Pemberi maaf //

Yang kedua adalah malaikat|artinya percaya kepada malaikat|asna itu artinya|diutus oleh Yang Agung|pekerjaannya menulis|perilaku para manusia|yang berdosa kecil dan besar|setiap malaikat memiliki tugas|semua malaikat //

Yang ketiga adalah kitab| artinya percaya terhadap semua|kitab Adam ada sepuluh| Nabi Esis memiliki 50 kitab|adapun kitab-kita itu| Edris memiliki 30 kitab| Ibrahim memilki 10 kitab| Taurat diturunkan nabi Musa, Zabur diturunkan kepada Nabi Dawud, Injil diturunkan kepada Nabi isa|Kitab Quran kepada Nabi Muhammad //

Dalam ketiga pada diatas menjelaskan bahwa kita harus percaya kepada Allah, percaya adanya malaikat juga percaya pada semua kitab yang diturunkan oleh para Nabi, dalam pada di atas tidak dijelaskan secara tersurat tentang wajibnya memercayai nabi, akan tetapi dengan tersuratnya "Yang ketiga adalah kitab|artinya 
percaya terhadap semua kitab" berarti perlunya memercayai adanya nabi-nabi yang menurunkan kitab-kitab tersebut.

\section{Nilai-nilai Pragmatik dalam Serat Kidung Ranggasutrasna}

Naskah $K R$ memiliki banyak fungsi esoteris bagi masyarakat pembacanya. Aspek esoteric inilah yang akan melahirkan kekuatan gaib bagi pembacanya. Di antara fungsinya adalah untuk melindungi bahaya, menolak berbagai hama, pengobatan penyakit, melindungi bayi dari bahaya dan gangguan, mempermudah cari jodoh, melindungi diri dalam peperangan, menjaga diri pada malam hari, membantu meringankan dan membebaskan belenggu hutang, dan lain-lain. Secara rinci fungsi teks $K R$ adalah sebagai berikut.

\section{KR Berfungsi untuk Melindungi Bahaya Malam Hari.}

Dalam kehidupan ini manusia seringkali menemukan bahaya yang datang secara tiba-tiba, baik pada waktu siang maupun malam hari. Dalam QS. Al Falaq disebutkan, "dan dari kejahatan malam apabila telah gelap gulita" (Qs. Al Falaq: 3. Potongan ayat di atas memerintahkan kita untuk mewaspadai datangnya malam. Artinya bahwa waktu datangnya malam itu banyak mendatangkan bahaya bagi manusia. Di antara bentuk-bentuk bahaya malam adalah kejahatan seperti perampokan, pencurian, pemerkosaan, perzinaan, pembunuhan, perjudian, dan lain-lain. Di samping itu, terdapat pula kewjahatan dan bahaya malam hari, seperti ganguan makhluk halus, gangguan setan, iblis, dan jin yang sengaja datang untuk mengganggu manusia.

Dalam hubungan ini terdapat hadis Nabi SAW yang mendukung keyakinan masyarakat tersebut adalah hadis Jabir bin Abdullah ra, bahwasanya Rasulullah bersabda:

"Tutuplah oleh kalian bejana bejana, rapatkanlah tempat tempat minuman, tutuplah pintu-pintu, dan matikanlah lampu. Karena setan tidak dapat membuka ikatan tempat minum, pintu dan bejana. Jika kalian tiadak mendapatkan penutupnya kecuali membentangkan sepotong kayu diatas bejananya dan menyebut nama Allah, maka lakukanlah. Karena tikus dapat merusak pemilik rumah dengan memebakar rumahnya." (HR Muslim)

Berkaitan dengan fungsi teks $K R$ yang menyatakan bahwa $K R$ berfungsi untuk melindungi bahaya di waktu malam. Dalam teks $K R$ secara jelas tertulis syair dalam pada pertama pupuh Dhandhanggula (1) yakni sebagai berikut. 
"ana kidung rumêksa ing wêngi | têguh ayu luputa ing lara|luputa bilai kabèh | jim setan datan purun | panêluhan tan ana wani | miwah panggawe ala $\mid$ gunaning wong luput $\mid$ gêni atêmahan tirta $\mid$ maling adoh tan ana ngarah mring mami | guna duduk pan sirna ||"

Artinya: "Ada nyanyian yang menjaga di waktu malam|aman sentosa bebas dari penyakit|bebas dari semua penderitaan (petaka) /jin dan setan tidak ingin mengganggu|santet tidak berani mendekat|dan semua perbuatan jahat/ gunaguna dari orang tersingkir|api menjadi air|pencuri jauh tidak ada yang mendekat (kepada-Ku)/ maksud jahat akan sirna |"

\section{KR Berfungsi Membebaskan Belenggu Hutang}

Dalam teks $K R$ terdapat mantra atau doa permohonan kepada Allah Swt untuk menghindari dan membebaskan seseorang dari belenggu hutang, pernyataan ini tersirat dalam pupuh dhandhanggula (1) pada ke tujuh yakni:

"lamun ana wong kadhêndha kaki | wong kabônda wong kabotan utang |yogya wacanên dèn age | nalika têngah ndalu| ping sawêlas wacanên singgih | luwar ingkang kabônda | kang kadhêndha wurung | aglis nuli sinauran |mring Hyang Suksma kang utang puniku singgih | kang agring nuli waras ||

Artinya: Jika ada orang didenda anakku|orang yang ditahan atau orang terlalu banyak hutang|sebaiknya bacalah segera|ketika di tengah malam|bacalah sebelas kali sesungguhnya|akan terlepas bagi yang ditahan|yang didenda akan urung|segera dikembalikan hutangya| oleh Tuhan dia yang berhutang itu sesungguhnya|yang sakit segera sembuh\|

Denda yang dimaksudkan dalam syair mantra tersebut adalah sebuah hutang. Hutang atau dalam bahasa Arab Ad-dain merupakan transaksi yang dilakukan oleh kedua belah pihak, yang mana salah satu pihak memberikan kewajibannya secara kontan (langsung). Sedangkan pihak keduanya memberikan kewajibannya pada kesempatan lain. Hutang terbagi menjadi dua yaitu hutang duniawi dan hutang akhirat. Hutang duniawi adalah hutang yang terjadi antar manusia baik berupa materi maupun utang budi. Sedangkan hutang akhirat adalah hutang yang terjadi antara manusia dengan Tuhannya. Hutang yang berhubungan dengan Tuhan tersebut biasanya berbentuk amalan yang belum terlaksanakan. Misalnya seseorang bernadzar dan belum melunasi nadzarnya. Sehingga dalam hidupnya biasanya diselimuti kesusahan dan kegelisahan. Dengan membaca $K R$ di waktu tengah malam sebanyak sebelas kali yang telah disebutkan dalam syair tersebut di atas, maka kidung ini akan membebaskan manusia dari hutangnya dan hidupnya tenang, tidak gelisah dan tidak terbelenggu pikiran yang menggangu selama ini. Mendendangkan atau membacakan 
kidung sebelas kali (dalam bahasa Jawa sewelas), sebenarnya memiliki makna yakni agar mendapat kewelasan (belas kasih) dari Allah Swt.

Dalam hubungannya dengan hutang tersebut ada sebuah cerita dari Abu Sa'id Al-Khudri r.a. diriwayatkan bahwa pada suatu hari Rasullullah SAW memasuki masjid. Tiba-tiba ada seorang pemuda yang sudah duduk lama didalam masjid, pemuda itu bernama Abu Umamah. Rasullulah Saw bertanya kepadanya, "Wahai Abu Umamah, mengapa aku melihatmu duduk di masjid pada waktu-waktu di luar shalat?" Abu Umamah menjawab “ Aku sedang dilanda kesususahan dan dililit hutang-hutang wahai Rasulullah.” Rasulullah kemudian bersabda "Ketahuilah aku kan mengajarakan kepadamu ucapan yang apabila engkau mengucapkannya, maka Allah SWT akan menyingkirkan kesedihan dan membayarkan hutang-hutangmu. Ucapkanlah pada waktu pagi dan sore."

"Allahumma inni a'udzubika minal hammi wal hazani wa a'udzubika minal 'ajzi wal kasali wa a'udzubika minal jubni wal bukhli wa a'udzubika min ghalabatiddaini wa qahrirrijali",

"Ya Allah saya berlindung kepada Engkau dari kesusahan dan kesedihan, saya berlindung kepada Engkau dari kelemahan dan kemalasan, saya berlindung kepada Engkau dari kepengecutan dan kekikiran dan saya berlindung kepada engkau dari himpitan hutang dan paksaan orang."

\section{$K R$ Berfungsi untuk Penolak Hama}

Sebagian besar masyarakat Jawa pedalaman berprofesi sebagai petani dan sering diresahkan oleh adanya serangan hama. Untuk menghindari serangan hama tidak dengan memusnahkan karena dengan memusnahkan akan memutuskan keseimbangan ekosistem yang ada. Di dalam teks $K R$ terdapat pada yang menjelaskan bagaimana cara menghindari serangan hama dengan tidak memusnahkannya. Hal tersebut dijelaskan dalam pada 8 pupuh dhandhanggula (1) yang berbunyi seperti berikut.

"lamun arsa tulus nandur pari | puwasaa sawêngi sadina | idêrana galêngane | wacanên kidung iku | sakèh ngama sami abali | "

Artinya: Jika kamu ingin sukses menanam padi/ berpuasalah sehari semalam|kelilingilah pematangnya/ bacalah kidung itu|semua hama akan kembali "”.

Pada baris pertama yang bunyinya "Jika kamu ingin sukses menanam padi" menjelaskan bahwa "kamu" dalam kalimat tersebut yakni petani yang menanam padi yang membacakan kidung tersebut, dan baris kedua dan ketiga merupakan cara dan ritualnya yakni dengan puasa sehari semalam, selanjutnya dibacakan atau didendangkan dengan cara mengelilingi ladang pertaniannya. Baris keempat 
menyebutkan semua hama akan kembali, maksudnya akan pergi, kembali ketempat singgahannya tidak jadi memakan hasil panen petani.

\section{KR Berfungsi untuk Meminta Pertolongan dalam Berperang}

Dalam teks $K R$ juga terdapat sebuah mantra yang isinya menjelaskan ritual atau cara agar mendapatkan pertolongan pada saat berperang, hal tersebut terdapat dalam pada ke delapan pupuh dhandhanggula (1) lanjutan dari gatra sebelumnya mengenai $K R$ yang berfungsi sebagai penolak hama. Yang berbunyi:

"yèn sira lunga pêrang | watêkên ing sêkul | antuka tigang pulukan | mungsuhira rêp-sirêp tan ana wani | rahayu ing payudan ||"

| jika kamu akan pergi berperang|bacakan pada nasi|sampai dapat tiga suapan|musuhmu akan terpengaruh tidak akan ada yang berani|sehingga selamat dalam pertempuran\|

Dalam pada di atas dijelaskan bahwa mantra atau doa yang diharapkan dalam kidung tersebut yaitu agar terbebas dari perang, dengan cara membacakan atau mendendangkan kidung dihadapan sajian nasi, diharapkan agar nasi ikut menyerap fungsi mantra atau doa kidung dan jika dimakan akan mengeluarkan efek berupa tenaga yang membangkitkan kekuatan gaib, sehingga perang berakhir dengan kemenangan. Pada syair selanjutnya menjelaskan "sampai dapat tiga suapan|musuhmu akan terpengaruh tidak akan ada yang berani”. Tersurat bahwa selain mendendangkan di hadapan nasi, setelah memakan hingga tiga suap akan membuat musuh saat berperang tidak berani. Perang yang dimaksudkan dalam $K R$ ini terlihat bahwa perang yang dimaksud adalah perang fisik.

Dapat disimpulkan bahwa $K R$ memiliki kesinambungan antara doa-doa yang ada di Al-Quran. Terbukti lagi dalam teks $K R$ menyebut nama Allah Swt, yang bunyinya : "sarap sawane tan wani | saking rahmate Hyang Suksma|lan supangate jêng nabi ||" yang artinya "tidak ada penyakit yang mendekat|karena rahmat Yang Maha Kuasa|dan syafaat nabi ||". Memang sesungguhnya $K R$ dibuat atas ajaran Islam berdasarkan syariat Nabi Muhammad Saw, yang dituangkan dalam bentuk kidung sehingga terangkai seperti sebuah mantra.

\section{KR Berfungsi untuk Menyembuhkan Penyakit dan Wabah Penyakit.}

Penyakit digolongkan menjadi dua yaitu penyakit rohani dan jasmani. Penyakit rohani atau disebut juga dengan penyakit hati disebabkan oleh dua perkara yakni ilmu 
yang rusak dan tujuan yang rusak. Dua perkara ini memunculkan dua penyakit yakni kesesatan dan kemarahan. Dua penyakit tersebut yang memicu datangnya penyakit hati dan biasanya juga dapat memicu timbulnya penyakit jasmani ditubuh penderita. Penyakit jasmani yaitu penyakit yang penangananya dilakukan secara medis, seperti dengan meminum obat atau pergi ke dokter demi mendapatkan kejelasan mengenai penyakitnya dan mendapatkan obat untuk penyembuhannya. Selain kedua penyakit di atas ada pula penyakit yang datangnya dari hal hal yang tidak kasat mata. Penyakit yang disebabkan oleh ilmu gaib, santet dari dukun dan lain sebagainya yang biasa dikenal dengan penyakit guna-guna.

Dalam teks $K R$ terdapat mantra doa untuk menyembuhkan penyakit dan membebaskan dari wabah penyakit salah satunya tersurat dalam Pupuh dhangdanggula (1) pada 26 dan Pupuh dhangdhanggula (1) pada 28 yang bunyinya:

"yèn kinarya atunggu wong sakit | êjim setan datan wani ngambah | rinêksa malaekate| nabi wali angêpung | sakèh lara padha sumingkir| ingkang sêdya pitênah | marang awak ingsun | rinusak dening Pangeran | iblis lanat sato mara mara mati | tumpês tapis sadaya ||"

Artinya:

Jika dibuat sebagai penunggu orang sakit|jin tidak berani mendatangi|dijaga malaikat|nabi dan wali mengitari|semua penyakit menyingkir semua|yang bermaksud memfitnah|kepada diriku|dihancurkan oleh Tuhan|iblis laknat dan binatang yang mencoba mendekati akan mati|semua ditumpas sampai habis \|

Pupuh dhangdhanggula (1) pada 28

sakathahing upas tawa sami | lara raga waluya nirmala | tulak tanggul kang manggawe | duduk samya kawangsul| akawuryan sagunging pikir| ngadam makdum sadaya | datan paja ngrungu | pangucap lawan pangrasa | myang tumingal kang sêdya tumêkèng napi | pangrêksaning malekat ||

Segala racun menjadi tawar|sakit badan akan sehat tanpa cela|menjadi tanggul penolak yang membuat|semua bahaya akan kembali|cerah semua pikiran|tidak ada ilmu semuanya|tidak mendengar sedikitpun|ucapan dan perasaan|penglihatan yang bermaksud mencapainya|dijaga oleh malaikat \|

Dua pada d atas menjelaskan bahwa $K R$ berfungsi untuk membebaskan diri dari segala penyakit. Baik yang bersifat fisik maupun kejiwaan. Karena itu, di dalam baitnya dinyatakan dengan tegas bahwa kidung ini menyelamatkan diri dari penyakit, semua petaka, jin dan setan dan perbuatan yang salah. Guna-guna pun menjauh. Dijelaskan pula bahwa dengan membaca atau mendendangkan mantra doa $K R$ ini, Nabi dan malaikat akan menjaga sehingga semua penyakit menyingkir. 
Hubungannya dengan kidung ini Sunan Kalijaga dan ronggrasutrasna menyusun $K R$ atas ajaran yang telah diajarkan Nabi Muhammad Saw dengan bentuk sebuah kidung agar masyarakat Jawa pada saat itu mau dan mampu memahami maksud dari apa yang diajarkan. Hal ini tersirat dalam pupuh dhandhanggula (1) pada 2 dan tiga yang bunyinya:

"sakèhing lara pan samya bali| sakèh ngama pan sami miruda|wêlas asih pandulune | sakèhing braja luput | kadi kapuk tiba ing wêsi| sakèhing wisa tawa $\mid$ sato galak tutut| kayu aèng lêmah sangar| songing landhak guwaning wong lêmah miring | myang pakiponing mêrak ||"

"pagupakaning warak sakalir | nadyan arca myang sagara asat | têmahan rahayu kabèh | apan sarira ayu | ingidêran kang widadari| rinêksa malaekat | sakathahing rusul | pan dadi sarira tunggal | ati Adam utêkku Bagendha Êsis | pangucapku ya Musa \|”

Artinya : Segala penyakit akan kembali | segenap hama akan sirna|dengan pandangan yang memancarkan belas kasih/segala senjata tidak akan mengenai|seperti kapas jatuhnya di besi|semua bisa akan tawar /musuh yang ganas akan tunduk (hancur)|pohon besar dan tanah angker|lubang landak dan gua orang yang bertempat di tanah miring|dan menjadi sarang burung merak// Kubangan tempat berendam badak| sekalipun patug dan lautan surut|pada akhirnya selamat semua| sebab tubuh mendapatkan keselamatan/ dikelilingi bidadari| dijaga malaikat|semua rasul| menjadi satu tubuh|hati Nabi Adam, otakku Nabi Esis|ucapanku Ya Musa \|.

Disebutkan bahwa kayu ajaib, tanah angker tanah miring, liang landak, sarang merak dan kandang badak, batu dan laut mengering; akan mendapatkan keselamatan semua. Badan menjadi selamat karena dikelilingi oleh para bidadari, malaikat dan para Rasul (yang berada didalam naungan Allah yang Maha melindungi) dalam syair di pada 2 dan 3 tersebut $K R$ memang tidak tersurat bahwa Allah yang Maha menaungi, tetapi adanya para rasul, malaikat dan bidadari bidadari yang membuktikan bahwa Allah Swt lah yang mengutus mereka. Karena semua yang ada didunia ini merupakan ciptaan Allah.

Hyang Suksma disini yang dimaksud yaitu Allah Swt Yang Maha Kuasa. Dzat yang membuat kehidupan. Selain pupuh diatas masih terdapat dalam teks $K R$ mengenai fungsinya untuk menyembuhkan penyakit yakni tersurat dalam pada 5 pupuh dhandhanggula (2) yang bunyinya:

"lan dèn dohkên sakèhing bilai | sinung rahmat ing donya ngakerat | sarta linêbur dosane | lan malih sawabipun | lamun ana jalma kang sakit | lan sira wacakêna | ngulon-ulonipun | ngalamat ingkang alara | olèh tômba saking sabdaning Hyang Idhi | lan barkahing panutan ||

Artinya: 
"Dan jauh dari semua dosa|mendapatkan rahmat di dunia dan akhirat|serta terhapus dosa- dosanya|dan lagi manfaatnya|ada juga manusia yang sakit|dan dan kamu bacakanlah|di ubun-ubunnya|tertuju pada yang sakit|mendapatkan obat dari Yang Maha Esa|dan mendapatkan berkah \|"

$P a d a$ di atas lebih menjelaskan ritual yang dilakukan dalam menggunakan $K R$ yaitu dengan membacakan $K R$ di ubun ubun si penderita dan diyakini akan mendapat obat dari yang Maha Esa dan semoga mendapatkan berkah. Kembali pada keyakinan seseorag bahwa dalam pengobatan segala penyakit, harus didasari dengan keyakinan, kepasrahan, dan keikhlasan dalam hati. Jika kita sudah berusaha dan berdoa sebaiknya pasrah dan yakin bahwa Allah Swt akan menyembuhkan.

\section{KR Berfungsi untuk Melindungi Bayi}

Dalam $K R$ terdapat syair kidung yang bukan termasuk mantra tetapi lebih kepada tata cara mengenai cara menjaga dan melindungi bayi. Hal tersebut tersurat dalam pupuh Kinanthi pada 1-5 yang bunyinya:

(1) yèn anangis lare iku | lela-lelanên lan dhikir| supaya doh kang lêlara | sarap sawane tan wani | saking rahmate Hyang Suksma | lan supangate jêng nabi $\|$

Artinya:

Apabila ada anak menangis|buailah dan dzikir|supaya jauh dari penyakit|tidak ada penyakit yang mendekat|karen rahmat Yang Maha Kuasa|dan syafaat nabi \|

(2) winacaa puji iku | setane lumayu gêndring | sarap sawane sumimpang | kala-kalane sumingkir | cacing racak padha mêndhak | krêmi kruma padha mati $\|$

Artinya:

Bacakan puji-pujian itu|setan pergi menjauh|penyakit bisa menghilang|mara bahaya menyingkir|cacing dalam tubuh menjauh|bakteri bakteri mati \|

(3) pitik tulak pitik tukung | têtulaking jabang bayi| ngêdohakên cacing racak | sarap sawane sumingkir | si tukung mangungkung ngarsa | si tulak bali ing margi ||

Artinya:

Ayam tukung|sebagai tumbal untuk bayi|menjauhkan dari cacing penyakit|mara bahaya menyingkir /ayam tukung sebagai tumbal|penolak berbagai penyakit \|

(4) si jabang bayi puniku | kêkasihira Hyang Widhi| rinêksa ing malaekat | dèn êmong ing widadari | pinayungan ing Hyang Suksma | kinêbutan para nabi $\|$

Artinya:

Si Bayi itu|merupakan kekasih Yang Maha Esa|dikuasai Malaikat|diasuh bidadri dalam naungan Yang Maha Kuasa|disayang para nabi $\|$ 
(5) sakathahe wali kutup | ngulama lan para mukmin | samya angrêksa ki jabang | mila têbih ing sêsakit | sirna larane ki jabang | walagang slamêt ki bayi $\|$

Artinya:

Sebanyak banyaknya wali|para ulama dan mukminin|saling menyayangi si bayi|maka dari itu jauh dari penyakit|hilang penyakitnya si bayi|semoga bayi senantiasa selamat\|.

Dari syair kidungan di atas dijelaskan bahwa jika ada anak yang menangis bacakanlah dzikir pun puji-pujian agar tenang dan dijauhkan dari penyakit. Karena biasanya anak akan menangis jika sedang merasa sakit pada badannya, maka dalam syair $K R$ tersebut memerintahkan agar sering dibacakan dzikir dan pujia-pujian agar peyakit tak ada yang mendekat atas rahmat Allah Swt.

Dzikir yaitu mengingat Allah, baik dilakukan dalam hati, ucapan, maupun tindakan yang menyucikan dan memuliakan Allah Swt. Dalam teks terdapat pada yang menjelaskan arti dzikir, tersebut tersurat dalam pada 8 pupuh Kinanthi yang bunyinya:

têgêse dhikir puniku | manut marang Kangjêng Nabi | Mukhamadinil mustapa | kalawan maknaning dhikir | eling mring Pangeranira|kang Agung kang Maha Suci \|

Artinya: Arti dan Dzikir|menurut para Nabi Mukhamadinil mustapa|memaknai dzikir|ingat kepada Tuhan|Yang Maha Agung dan Maha suci $\|$

\section{$K R$ Berfungsi untuk Mempercepat Jodoh Perawan Tua}

Menikah merupakan sebuah Impian setiap manusia, kekhawatiran yang muncul lebih sering dialami oleh seorang perawan yang sudah dewasa jika belum menikah. Setiap wanita dewasa yang sudah beranjak memasuki usia 30 tahun biasanya sudah mulai resah jika dirinya belum juga mendapatkan jodoh atau pendamping hidupnya. Saat itulah wanita memasuki masa kritis dimana sebenarnya usia matang untuk menikah adalah sekitar 25 - 29 tahun. Di atas usia 29 tahun sudah timbul masalah berupa keresahan tak akan menemukan jodoh. Jodoh merupakan takdir dari Allah yang sudah ditetapkan, namun ikhtiyar dalam mendapatkan jodoh atau pasangan hidup wajib dilakukan. Dalam teks $K R$ terdapat syair yang terkait mengenai mempercepat jodoh pada perawan tua, yaitu dalam pupuh dhandhanggula (1) pada 3 yang bunyinya:

wiji sawiji mulane dadi | apan pêncar saisining jagad| kasamadan dening dzate| kang maca kang angrungu| kang anurat kang animpêni 
| dadi hayuning badan | kinarya sêsêmbur | yèn winacakna ing toya | kinarya dus rara tuwa gêlis laki | wong edan nuli waras ||

Artinya: Ada satu benih akhirnya berhasil jadi|sebab disebar keseisi dunia|dikabulkan oleh dzatnya|semua yang membaca dan mendengar|yang menulis dan menyimpannya|itu menjadi keselamatan diri|bisa juga dibuat semprotan penyembuh|jika dibacakan di air|lalu dipakai mandi perawan tua dia akan cepat menikah|orang gila akan sehat $\|$.

Dijelaskan bahwa dengan membaca atau mendengarkan kidung akan menjadi selamat dan jika dibacakan pada air dan digunakan untuk mandi seorang perawan tua diyakini perawan tua tersebut akan segera mendapatkan jodoh dan menikah. Disini penulis menyimpulkan bahwa kekuatan air yang dibacakan atau didoakan dengan $K R$ sangat ampuh untuk digunakan sebagai obat atau penyembuhan. Karena memang air merupakan benda mati yang sebenarnya hidup, ia akan membentuk suatu molekul kristal yang indah jika dibacakan atau dibisikan kata kata yang indah dan baik. Sebagaimana telah disebutkan dalam firman Allah Saw: "Dan Kami ciptakan dari air segala sesuatu yang hidup." (QS Al-Anbiya: $30)$.

\section{Simpulan}

Selain beberapa fungsi kekuatan gaib tersebut di atas, teks $K R$ memiliki fungsi lain, seperti fungsi hiburan, spritual dan pendidikan berikut.

1. Fungsi hiburan

$K R$ dalam khazanah sastra merupakan macapat yang berfungsi sebagai sekar waosan, sekar waosan adalah teks-teks serat atau babad yang dibacanya dengan cara dilagukan atau sebuah aktivitas membaca serat dan babad dengan cara dilagukan.

\section{Fungsi spiritual}

$K R$ dalam fungsi spiritual sudah jelas terlihat dari pupuh awal hingga akhir yang isinya terkait dengan ajaran ajaran islam, sebenarnya $K R$ ini merupakan serat yang pada zaman dahulu sebagai alat penyebaran agama islam yang dilakukan oleh Sunan Kalijaga. Pasalnya jika diperhatikan dengan seksama, melalui syair awal $K R$ dalam pupuh dhandhanggula, pupuh tersebut merupakan inti dari tersusunya $K R$ hingga akhir. Terbukti dari beberapa fungsi diatas yang telah penulis paparkan, sebagian besar tersurat dalam pupuh dhandhanggula (1). Fungsi 
sipritual terlihat dalam pada awal yang menjelaskan bahwa terdapat perlindungan dimalam hari, syair yang dibuat oleh Sunan Kalijaga bermaksud mengajarkan dan mengajak manusia agar terjaga dimalam hari, lalu kemudian melakukan ritual ibadah dan melantunkan tembang.

3.Fungsi pendidikan

Seperti yang sudah dipaparkan pada subab diatas dalam kandungan teks bahwa selain mantra dan doa dalam teks $K R$ terdapat pada yang isinya pengajaran mengenai ilmu Islam yaitu mengenai rukun Iman. Teks $K R$ mengajarkan kepada masyarakat agar memiliki keimanan, ketakwaan dan berwatak keutamaan yang menuju ke arah etos pendidikan yang baik.

\section{Daftar Pustaka}

Abdullah, Muhammad, 1992. Kesenian Blantenan : Kesenian Tradisional Dalam Tradisi Pesantren di Kaliwungu Kendal. Semarang : Laporan Penelitian Lemlit UNDIP. , 1996. "Puji-pujian : Tradisi Lisan Dalam sastra Pesantren” dalam WARTA ATL. Jakarta : Jurnal ATL. 2004. Meretas Ziarah. Kendal : Panitia Festival Al-Muttaqin. 2006. Dekonstruksi Sastra Pesanren. Semarang : Fasindo. 2010. Khasanah Sastra Pesisir. Semarang : Penerbit Undip Press.

Abdurrahman As-Suyuti, Jalaluddin, th Ar-Rahmah Fiththib wal Hikmah.

Ahmad, Abul Abbas, bin Ali Al-Buni, th Mamba'u Ushulul Hikmah.

Al-Ghazali, th Al-Munqid Minadzdzalal , (tanpa tahun). Al-Aufaq.

Al-Muthawwi, Jasim Muhammad. 2007. Hidup Sesudah Mati. Solo : Pustaka Arafah.

Azam, Abdullah, 1985. Ayatu Ar-Rahman Fi Jihad Al-Afghan. Kuala Lumpur : Mathb'ah Kazhim Dubai UEA.

Basuki, Anhari, 1988. "Sastra Pesantren" dalam Lembaran Sastra. Semarang : Fakultas Sastra UNDIP.

Hawwa, Said, 1996. Jalan Ruhani. Bandung : Mizan.

Mundzir, Muhammad Nadzir, (tanpa th). Singir Tajwij: Tanwiru 'l-Qari'. Surabaya : Al-Ashriyah.

Muzakka, Moh. 1994. "Singiran : Sebuah Tradidsi Sastra Pesantren" dalam Hayam Wuruk No. 2 Th. IX.

Padmosoekotjo, S. 1960. Ngengrengan Kasusastraan Djawa. Yogyakarta : Hien Hoo sing. 
Qurdi, Imam, (tanpa tahun). Tanwirul Qulub.

Singir Paras nabi. (tanpa th). Surabaya : Maktabah Said bin Nubhan wa Auladihi.

Soewignyo, R. Poerwo dan R. Wirawangsa. 1920. Pratelan Kawontenaning Boekoeboekoe Basa Djawi Tjitakaningkan Kasimpen Wonten ing Gedong Boekoe (Museum) ing Pasimpenan Bibliotheek XXXIII. Drukkerij Ruygrik and Co.

Sibawaihi, 2004. Eskatologi Al-Ghazali dan Fazlur Rahman : Studi Komparatif Epistemologi Klasik-Kontemporer. Yogyakarta : Penerbit Islamika.

Siraj, (anpa tahun). Syi'ir Erang-erang Sekar Panjang.

Teeuw, A. 1984. Sastra dan Ilmu sastra : Pengantar Teori Sastra. Jakarta : Pustaka Jaya.

Tim IAIN, 1993. Ensiklopedi Islam. Jakarta : PT Ichtiar Baru van Hoeve.

Thohir, Mudjahirin, 1997. Inventarisasi Sastra Pesantren di Kaliwungu Kendal. Semarang : Laporan Hasil Penelitian Lemlit UNDIP. 